\author{
한방안이비인후피부과학회지에 게재된 \\ 여드름과 관련된 논문에 관한 고찰 \\ 김지수 · 박수연 · 최정화 · 김종한 · 이두희 \\ 동신대학교 한의과대학 한방안이비인후피부과학교실
}

\title{
The Review on the Acne Related Articles Published in the Journal of Korean Medicine Ophthalmology, Otolaryngology \& Dermatology
}

\author{
Ji-Soo Kim · Soo-Yeon Park ·Jeong-Hwa Choi $\cdot J o n g-H a n$ Kim $\cdot$ Doo-Hee Rhee \\ Department of Ophthalmology, Otolaryngology \& Dermatology, College of Korean medicine, Dong-Shin University
}

\begin{abstract}
Objective : This study was carried out to analyze the trends of Acne related articles that have been published in the Journal of Korean Medicine Ophthalmology, Otolaryngology \& Dermatology(JKOOD).

Method : We studied 29 research papers relevant to Acne that published in JKOOD from 1998 to 2013. All the paper were classified into three categories; original article, review article and case report. We sub-classified the original articles into three categories; descriptive study, analytic study and experimental study. We analyzed the case report according to various types of treatment.

Results : 1 . The number of searched journals is 29 papers; 17 original ordicles, 4 review articles, 8 case reports.

2. Classification of 17 original articles into three categories; 10 experimental studies, 7 descriptive studies, 0 analytic study.

3. Method of Evaluation; Korean Acne Grading System(KAGS) is used frequently in descriptive studies and experimental studies.

4. Treatment in Case reports; 7 Case reports used External medical treatments.

Conclusions : It is needed to develop the methods of grading system in acne related to Oriental medicine to obtain objectivity of studies. The number of analytic study, clinical trial and experimental study is need to increase.

Key word : The Journal of Korean Medicine Ophthalmology, Otolaryngology \& Dermatology; Acne; Original article; Review article; Case report

(c) 2014 the Society of Korean Medicine Ophthalmology \& Otolaryngology \& Dermatology

This is an Open Access journal distributed under the terms of the Creative Commons Attribution Non-Commercial License (http://creativecommons.org/license/by-nc/3.0/) which permits unrestricted non-commercial use, distribution, and reproduction in any medium, provided the original work is properly cited.
\end{abstract}




\section{I. 서 론}

여드름은 털피지샘단위(pilosebaceous unit)의 만성 염증질환으로 피부과 외래를 방문하는 환자들에게 흔 하게 관찰되는 질환 중 하나이며 면포, 구진, 농포, 결 절, 가성낭종(pseudocyst) 등ํ) 다양한 병변이 피지 분 비가 많은 부위인 얼굴이나 목, 등, 어깨, 가슴에 나타 난다 ${ }^{1,2)}$. 여드름은 주로 사춘기에 발생하여 20세 중반 부터 소실되기 시작하지만, 최근에는 25 세 이후까지 지속되거나 새로 발생하는 성인기 여드름이 증가하고 있다 ${ }^{3)}$

현대사회에 이르러 미용에 대한 사람들의 관심이 급증함에 따라 심리적인 이유로 치료에 대한 요구가 높아져 다양한 치료법들이 나오고 있다. 일부 여드름 이 심한 환자들은 이로 인해 우울증, 불안, 자신감의 결여, 대인관계 기피 등 많은 심리적 영향을 초래하여 삶의 질에 부정적인 영향을 미칠 수 있단). 가역적 변 화를 주로 하는 경우와 心身症 경향을 수반하는 경우, 양방 치료 효과로 불충분한 경우 등이 한방 치료를 선호하는 경향이 높았으며 ${ }^{5}$ 한의학에서의 여드름은 痤, 面瘡, 肺風粉刺 등으로 보고 肺經風熱, 飲食不節, 脾失健運, 濕痰 등이 원인으로 제시되고 있다 ${ }^{6}$.

여드름의 치료에 대한 요구가 많아짐에 따라 다양 한 한의학적 치료 방법들이 개발되어 사용되고 있으 나 뚜렷한 방향성이나 일관된 치료법이 아직까지 미 흡한 상태이다. 한방안이비인후피부과 학회지에 보고 된 여드름 관련 논문을 통해 여드름의 한방 치료에 관하여 기존에 진행되어 온 연구들에 대한 분석으로 향후 여드름의 한의학적 치료에 대한 연구 방향을 모 색하고 발전시키고자 하였다.

교신저자 : 박수연, 전남 순천시 조례동

동신대학교 부속 순천한방병원 한방안이비인후피부과

(Tel : 061-729-7122, E-mail : swallow92@hanmail,net)

- 접수 2014/7/14 • 수정 2014/8/8 • 채택 2014/8/15

\section{II. 연구방법}

\section{1. 연구 대상}

연구 대상은 1998년 대한외관과학회지부터 2014년 도 27 권 2호까지 대한한방안이비인후피부과 학회지 (The Journal of Korean Medicine Opthalmology, Otolaryngology \& Dermatology)에 개재된 논문들 중, 대한한방안이비인후피부과 학회 홈페이지 논문 검색 페이지에서 여드름과 관련된 총 29편의 논문으 로 삼았다.

\section{2. 연구 방법}

이상의 검색된 29편의 논문들은 원저(Original article), 종설(Review article), 증례보고(Case Report) 논문으 로 분류하여 분석하였다. 원저(Original article)는 지 금까지 알려지지 않았던 새로운 사실의 발견, 새로운 연구방법의 개발 등과 관련된 타 학회지에 보고한 적 이 없는 수집된 자료결과를 포함하는 연구물이며, 종 설(Review article)은 다른 곳에 이미 보고된 문헌 자 료를 기초로 작성된 설명적 또는 해석적인 요약문이 며, 증례보고(Case Report)는 한명 이상의 환자에서 이루어진 관찰로 집단으로 모으거나 분석되지 않고 개별적으로 언급된 것을 말한닥.

원저 관련 논문들은 연구 형태, 연구에 사용된 한의 학적 치료 도구, 치료 대상 및 대상의 수, 치료 효과 평가 방법, 연구 기간, 연구 결과에 대해 살펴보고 사 용되는 치료 도구에 따른 치료 효과 결과를 조사하였 다. 종설 관련 논문들은 문헌 자료의 출처 및 성격에 따라 분류하고 문헌자료를 고찰한 목적에 대해 분석 하였다. 증례보고 관련 논문들은 치료에 사용된 한약, 침치료 방법, 기타 다른 외치법, 평가 도구, 치료 효과 에 대해 살펴보고 자주 사용되는 치료법과 치료 효과 에 대한 결과를 조사 하였다.

추가적으로 전체 논문에서 상대적으로 비중이 많은 원저와 증례보고 논문의 경향성을 비교하여 현재 자 
주 이용되는 한의학적 치료 방법과 빈도에 대해 조사 하였다.

\section{III. 결 과}

\section{1. 논문의 분류 및 경향}

본 학회지에 1998년 대한외관과학회지부터 2014년 도 27 권 2호까지 개재된 여드름과 관련된 29편 논문 중 원저가 17 편, 증례보고가 8 편, 종설이 4편으로 원 저 논문이 가장 많은 것으로 나타났다.

연도별로 봤을 때는 2008년에 5편, 2007년에 4편 으로 가장 많았으며 2005년에는 단한편의 논문도 없 었다. 연도별 경향으로 봤을 때, 2006년부터 원저 논 문을 중심으로 증가하는 추세를 보이다가 2009,2010 년에 다소 주춤한 후 2011년부터 2013년까지는 꾸준 히 3편씩의 논문이 개재 되었다.

논문 분류에 따른 연도별 경향은 원저 논문의 경우 2008년에 4편으로 가장 많고, 2001, 2004, 2005, 2010, 2012년에 0편이였던 것을 제외하면 꾸준히 한 두 편의 논문이 나왔던 것으로 나타났다. 증례보고 논 문의 경우는 2000 년부터 2007 년도까지 한편의 논문 만이 나왔으나 2008년 이후로 총 8편 중 7편이 개재 되는 증가 추세를 보였다(Table 1).

\section{2. 원저 논문 분석}

본 학회지에 개재된 원저 논문은 전체 29편 중 17 편(58.6\%)으로 많은 비중을 차지하고 있었다. 원저 논문을 기술적 연구(Descriptive Study), 분석적 연구 (Analytic Study), 실험적 연구(Experimental Study) 로 분류해보았을 때, 실험적 연구가 10 편으로 가장 많 았고 기술적 연구가 7편, 분석적 연구가 0 편이였다.

\section{1) 기술적 연구}

기술적 연구 논문은 치료 예후에 관한 보고 임상논 문이 5 편, 진단법에 관한 논문 1 편, 환자의 삶의 질을
Table 1. The Number of Articles Classified by Years and Purpose

\begin{tabular}{ccccc}
\hline Years & $\begin{array}{c}\text { Review } \\
\text { article }\end{array}$ & $\begin{array}{c}\text { Original } \\
\text { article }\end{array}$ & $\begin{array}{c}\text { Case } \\
\text { report }\end{array}$ & Frequency \\
\hline 2000 & 0 & 2 & 0 & 2 \\
2001 & 0 & 0 & 1 & 1 \\
2002 & 0 & 1 & 0 & 1 \\
2003 & 0 & 2 & 0 & 2 \\
2004 & 1 & 0 & 0 & 1 \\
2005 & 0 & 0 & 0 & 0 \\
2006 & 0 & 1 & 0 & 1 \\
2007 & 0 & 4 & 0 & 4 \\
2008 & 1 & 2 & 2 & 5 \\
2009 & 0 & 1 & 1 & 2 \\
2010 & 0 & 0 & 1 & 1 \\
2011 & 1 & 2 & 0 & 3 \\
2012 & 1 & 0 & 2 & 3 \\
2013 & 0 & 2 & 1 & 3 \\
\hline & 4 & 17 & 8 & 29 \\
\hline
\end{tabular}

평가한 논문이 1 편이 있었다. 사용된 내복 한약으로 는 갈근해기탕가감, 가감청상방풍탕이 주로 사용 되 었으며, 외용으로 사용된 치료제는 박하뇌와 백선피 유황 등으로 만든 외용제가 있었다.

연구기간은 10 일정도부터 길게는 12 개월까지 다양 한 기간동안 연구가 진행되었다(Table 2).

2) 실험적 연구

실험적 연구를 세포실험(Cell Experiment)과 동물 실험(Animal Experiment), 임상실험(Clinical trials) 으로 나누어 봤을 때, 실험적 연구 논문 10 편 중 세포 실험 5편, 동물 실험 3편, 임상 실험 2편으로 분류되 었다. 세포 실험은 5편 모두 P.acnes를 기본 여드름 원인균으로 설정하였으며, 동물 실험은 3 편 모두 ICR mouse를 실험체를 삼았다.

실험 논문에 사용된 시약은 탕약의 추출물을 사용 한 논문이 6편, 본초의 추출물을 사용한 논문이 4 편이 


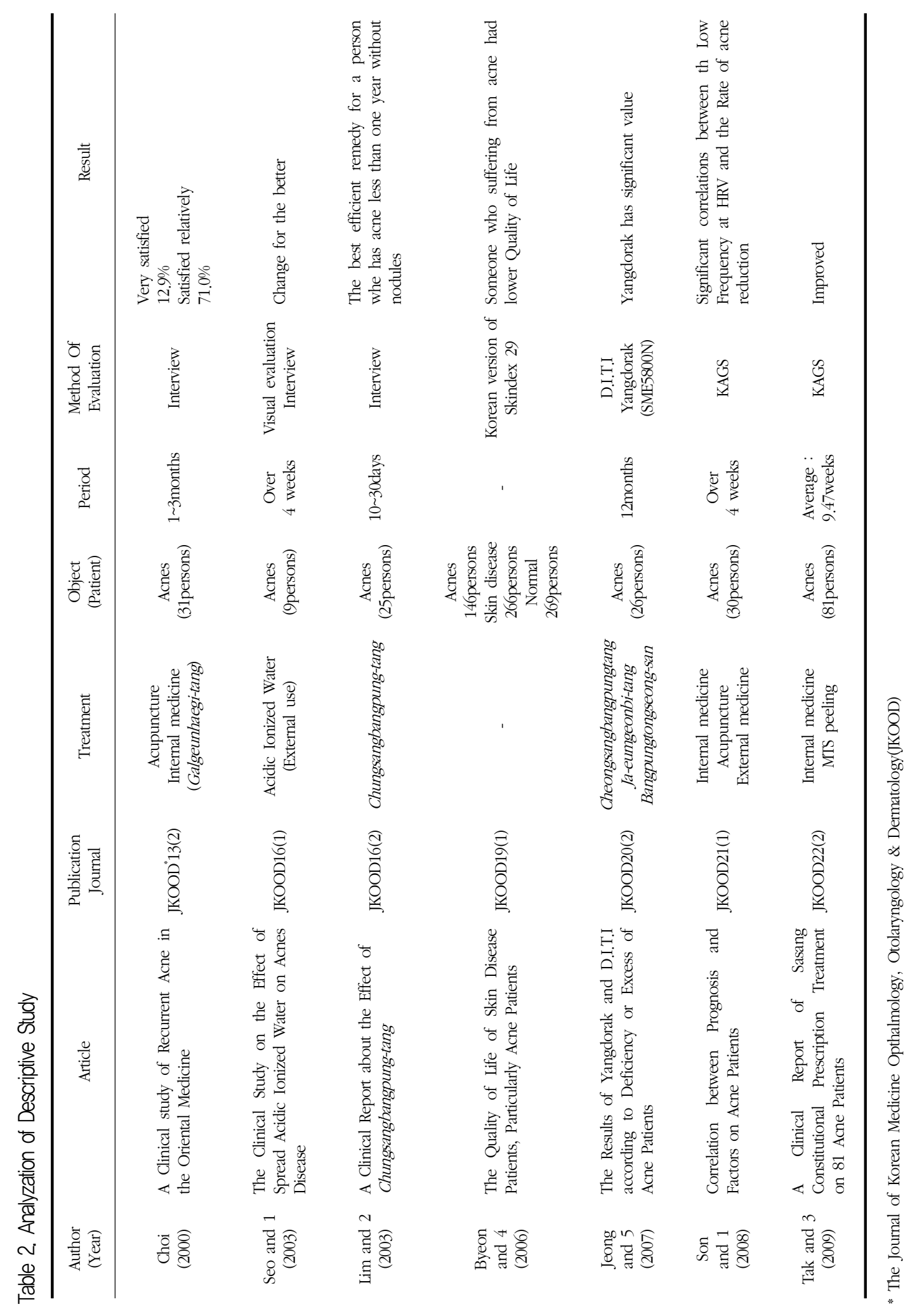

จ 


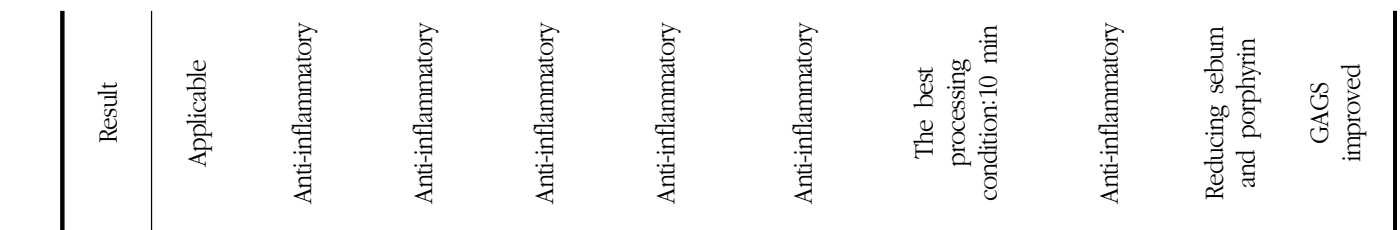

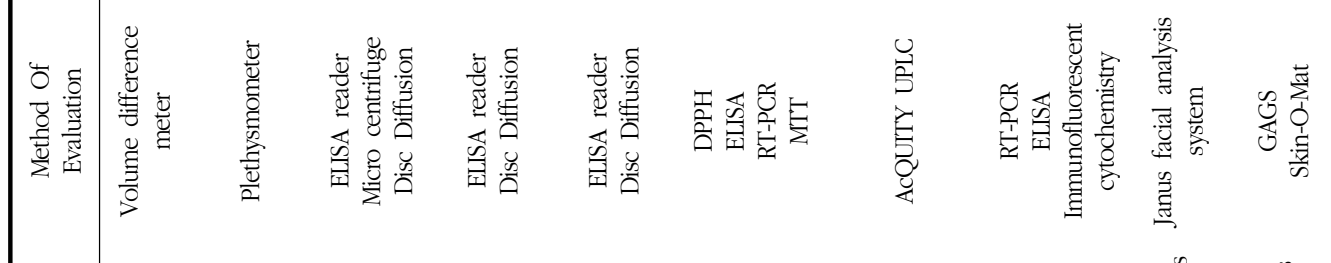

$$
\begin{aligned}
& \frac{\bar{o}}{\square}
\end{aligned}
$$

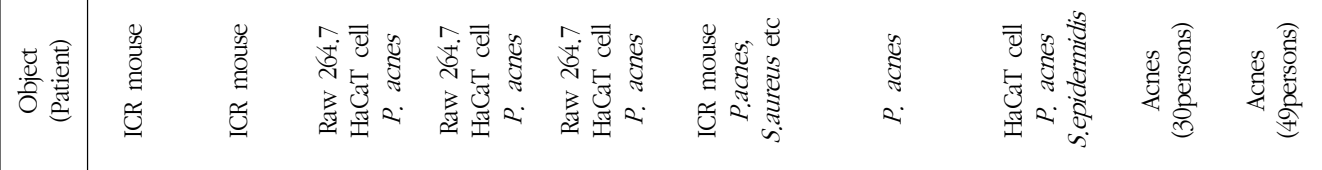

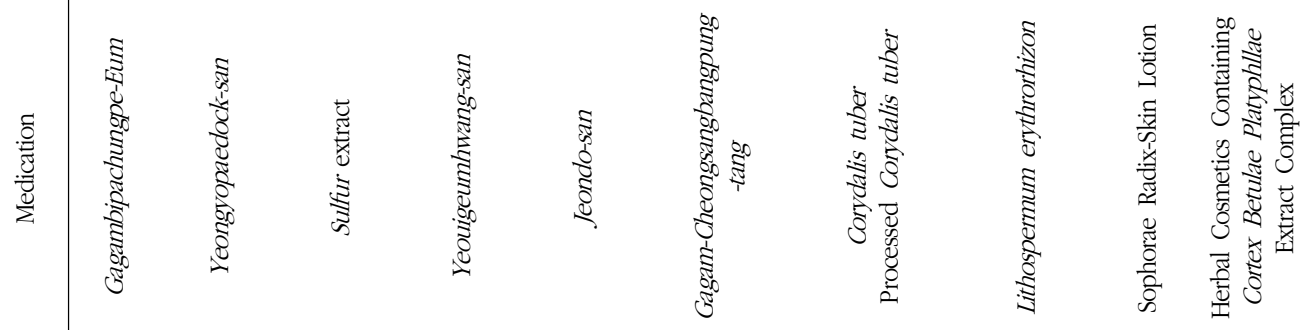

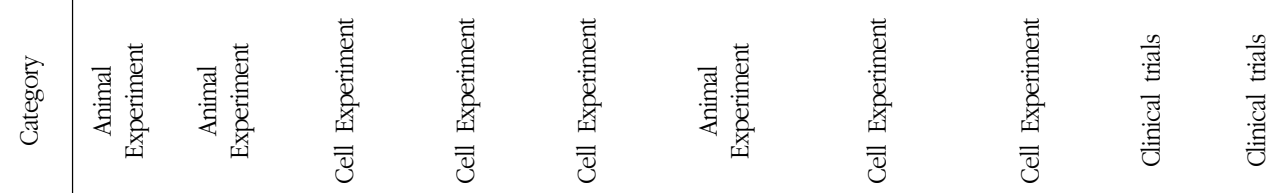

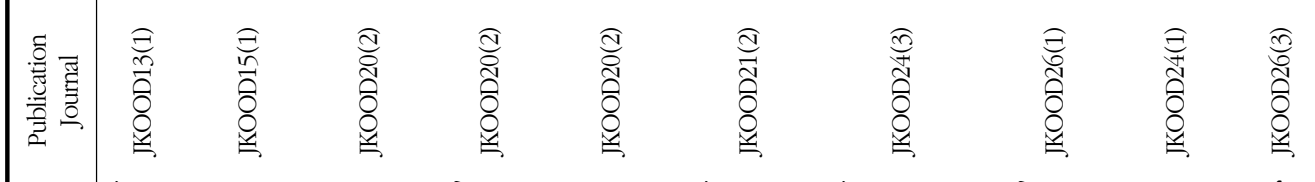

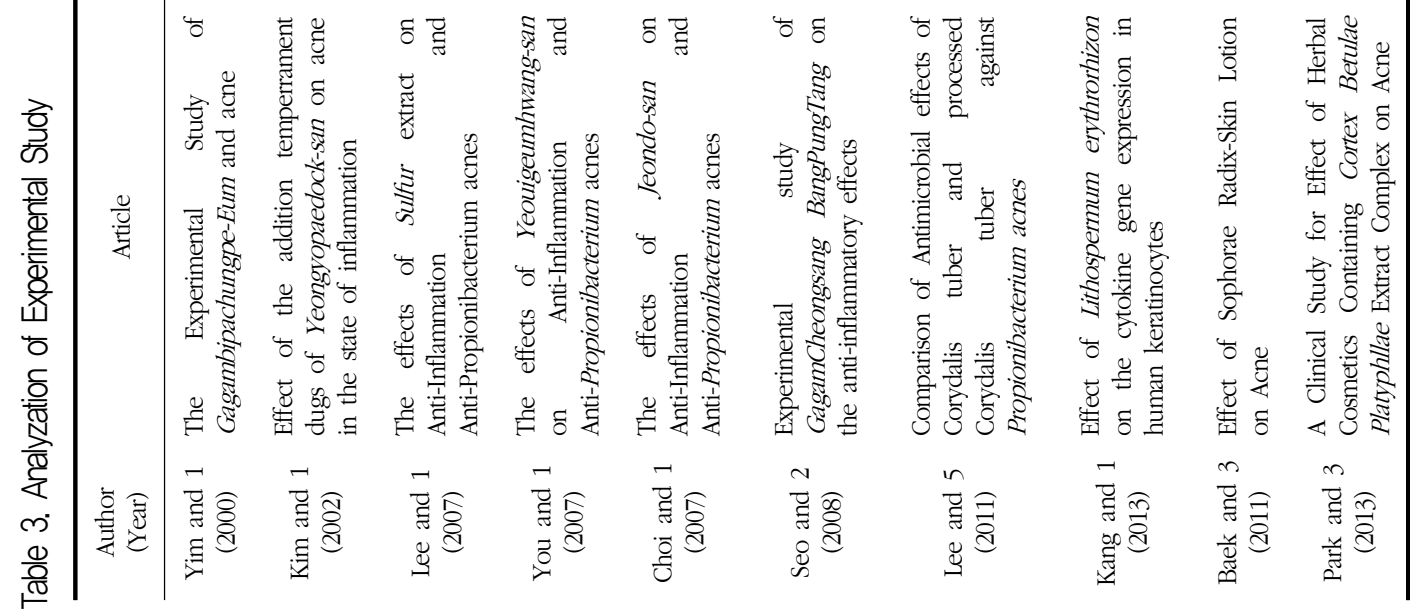


있었다. 탕약은 가감비파청폐음, 연교패독산가미방, 가감청상방풍탕, 여의금황산, 전도산이 사용되었으며, 본초는 유황, 현호색, 자초 등이 사용 되었다. 임상 실 험에서는 고삼추출물과 화피 추출물이 함유된 화장품 이 사용되었다(Table 3).

\section{3) 증례 표본 수}

기술적 연구와 실험적 연구의 임상실험 연구 중에 서 환자표본을 이용한 논문은 총 9편으로 기술적 연 구 7편과 임상실험 논문 2편이 있다. 그중 대부분이 20 30명대의 환자군(55.6\%)을 상대로 연구를 진행했 으며, 변 등은 일반인 535 명이라는 인원을 상대로 설 문지를 시행해 기술적 연구를 진행하였다(Table 4).

Table 4. Distribution of Patient in Original Article

\begin{tabular}{ccc}
\hline Patient & \multicolumn{2}{c}{ Frequency } \\
\hline $1 \sim 20$ & 1 & $11.1 \%$ \\
$21 \sim 40$ & 5 & $55.6 \%$ \\
$41 \sim 80$ & 1 & $11.1 \%$ \\
$81 \sim$ & 2 & $22.2 \%$ \\
\hline
\end{tabular}

\section{4) 평가 방법}

다양한 세포 실험, 동물 실험을 제외하고 환자를 대 상으로 한 기술적 연구와, 임상실험 논문 9편에서 여 드름에 사용한 평가 척도를 살펴보면 2003년도 이전 논문 3편은 문진과 육안평가 위주의 평가법를 사용했 고 2006년도 이후 논문에서는 Skindex-29만 사용한 논문이 1편, $\mathrm{KAGS}$ 를 사용한 논문 2편, 유분수치와 여드름 중증도 시스템(Global acnes grading system, GAGS)를 사용한 논문이 1편이 있었고 피지분비량과 포피린양을 사용한 논문도 있었다. 사용된 진단 기기 로는 Skin-O-Mat, Janus 안면진단기, Dermavision, 컴퓨터 체열 촬영기, 양도락 등이 있었다.

\section{3. 종설 논문 분석}

본 학회지에 개재된 종설 논문은 총 4편으로 2004 년 유, 최의 논문, 2008년 김 외 7명의 논문, 2011년 이 외 5 명의 논문이다.

문헌 출처로 구분지어 보면 국내 문헌을 중심으로 분석한 논문이 3편, 북미와 유럽 등의 해외 논문을 중 심으로 분석한 논문이 1 편이였으며, 고찰 문헌의 종류 별로 봤을 때 기존의 도서들을 통해 고찰한 논문 1편, 기존의 논문을 통해 고찰한 논문 2 편, 시중에 판매되 는 월간지를 통해 여드름 외용약을 고찰한 논문 1편 이었다.

목적 주제별로 구분지어 보면 2편의 논문이 여드름 의 외용약에 관한 논문이며, 한편은 여드름 치료와 관 련된 최신 임상 연구 동향에 관한 논문이며 나머지 한편이 병인과 증상, 치료법을 통괄 정리한 질환 자체 에 관한 논문이었다(Table 5).

\section{4. 증례보고 논문 분석}

본 학회지에 개재된 증례보고 논문은 전체 29편 중 8편(27.6\%)으로 많지 않지만 다양한 유형의 치험례들 이 보고되었다(Table 6). 이중 치료 목표를 여드름 흥 터에 맞춘 논문이 2편이 있었다.

\section{1) 한의학적 치료}

총 8편의 논문 중 한약 치료만을 단독 시행한 경우 는 1편(12.5\%) 이였으며, 침 치료를 단독 시행한 경 우는 4편(50\%), 한약과 침 치료를 병행한 경우 3편 (37.5\%) 중 병행하였으나 한약 위주의 치료인 경우는 2편이였다.

침 치료법을 시행한 7편의 논문 중 호침 치료를 시 행한 논문은 2편이며, 그 중 1편은 耳鍼을 동반하였 다. 나머지 5 편의 논문은 도장침 시행 1 편, 절개침 시 행 1편, 자동미세침법 시행 2편, 자동미세침법과 흥터 복원침법(절개침, 횡자침)을 병행한 경우 1 편으로 여드 름 흉터의 치험례의 경우 모두 절개침이 사용 되었다. 
한약 치료법을 시행한 4편의 논문 중 외용약을 사 용한 논문은 2 편이였으며 외용약과 내복약을 병행하 여 치료 하였다. 내복약만을 시행한 논문은 1 편으로 나타났다. 사용한 외용약으로는 면포산, 황련해독탕가 미 발효액이 있었고, 내복약으로는 청상방풍탕, 보중 익기탕가미, 도핵승기탕, 황련해독환, 영계감출탕, 삼 황사심탕가미, 소시호탕 등이 있었다.

기타 동반된 치료로는 압출이 4편으로 가장 많았고 그 외에 광역동, 앰플, 한방 마스크팩, 크림 등이 병행 된 것으로 나타났다.

\section{2) 평가 방법}

평가 방법은 대체로 통일 되어있었는데 2001년 김 외 1 의 논문 1 편을 제외하고 여드름 치험례 5 편은 한 국형 여드름 중증도 평가 시스템 KAGS(Korean Acne Grading System)를 사용 하였으며, 여드름 흥 터 치험례 2편 중 1편은 $\mathrm{KAGS}$ 와 여드름 흥터 질적 등급체계 QGASC(Qualitative Global Acne Scarring Grade System)를 병행 하였고 다른 1편은 정량적 흥 터 등급체계 GASC(Global Acne Scarring Classicication)를 사용하였다.

기타 평가 방법으로 문진이 4편으로 많이 사용되었 으며, 성 외 2 명의 논문은 Janus안면진단기, 체열진단 을 병행하여 사용하였다.

\section{IV. 고 찰}

여드름은 털피지샘단위(pilosebaceous unit)의 만성 염증질환이며 면포, 구진, 농포, 결절, 가성낭종 (pseudocyst) 등의 증상이 얼굴, 등, 어깨, 목에 주로 나타나는 질환이다. 사람의 $85 \%$ 가 12 25세 사이에 여드름을 경험하게 되고 20세 중반부터 소실되기 시 작하지만, 최근에는 25 세 이후까지 지속되거나 새로 발생하는 성인기 여드름이 증가하고 있닿. 다만 현 대사회에 이르러 미용에 대한 사람들의 관심이 급증 함에 따라 심리적인 이유로 치료에 대한 요구가 높아 져 다양한 치료법들이 나오고 있다. 양방에서는 주로 압출요법, 스테로이드 병변 내 주사, 항생제 국소 도 포, 비타민이나 Benzoyl peroxide 도포 등의 국소 요 법과 항생제 복용이나 이소트레티노인 같은 호르몬제 복용을 통해 치료하고 있달). 최근에는 각종 레이저 및 필링을 기반으로 한 여드름 치료법들이 주목받고 있으나 효과나 부작용에 대한 정립이 불완전한 상태 이다.

한의학에서의 여드름은 痤, 面瘡, 肺風粉刺 등으로 보고 肺經風熱, 飲食不節, 脾失健運, 濕痰 등이 원인 으로 제시되고 있다 ${ }^{6}$. 여드름의 치료에 대한 요구가 많아짐에 따라 다양한 한의학적 치료 방법들이 개발 되어 사용되고 있으나 뚜렷한 방향성이나 일관된 치

Table 5. Analyzation of Review Article into Subject, Reference

\begin{tabular}{|c|c|c|c|c|}
\hline Years & Author & Article & Subject & Reference \\
\hline 2004 & $\begin{array}{l}\text { You } \\
\text { and } 1\end{array}$ & $\begin{array}{l}\text { A Practical Application on the External Treatment of } \\
\text { Acne (A Focus on the Medical Herbs Published in } \\
\text { the Woman's Monthly Magazines) }\end{array}$ & Remedy & $\begin{array}{l}\text { Magazine } \\
\text { Korea }\end{array}$ \\
\hline 2008 & $\begin{array}{l}\text { Kim } \\
\text { and } 7\end{array}$ & $\begin{array}{l}\text { The study on external treatment of oriental medical } \\
\text { care on acne }\end{array}$ & Remedy & $\begin{array}{l}\text { Article } \\
\text { Korea }\end{array}$ \\
\hline 2011 & $\begin{array}{l}\text { Lee } \\
\text { and } 5\end{array}$ & $\begin{array}{l}\text { The Latest Trends of Treatment for Acne Vulgaris in } \\
\text { PubMed }\end{array}$ & Remedy & $\begin{array}{l}\text { Article } \\
\text { North } \\
\text { America } \\
\text { Europe }\end{array}$ \\
\hline 2012 & $\begin{array}{l}\text { Joo } \\
\text { and } 2\end{array}$ & $\begin{array}{l}\text { A Literature Study about Comparison of } \\
\text { Eastern-Western Medicine on the Acne }\end{array}$ & Disease & Book \\
\hline
\end{tabular}




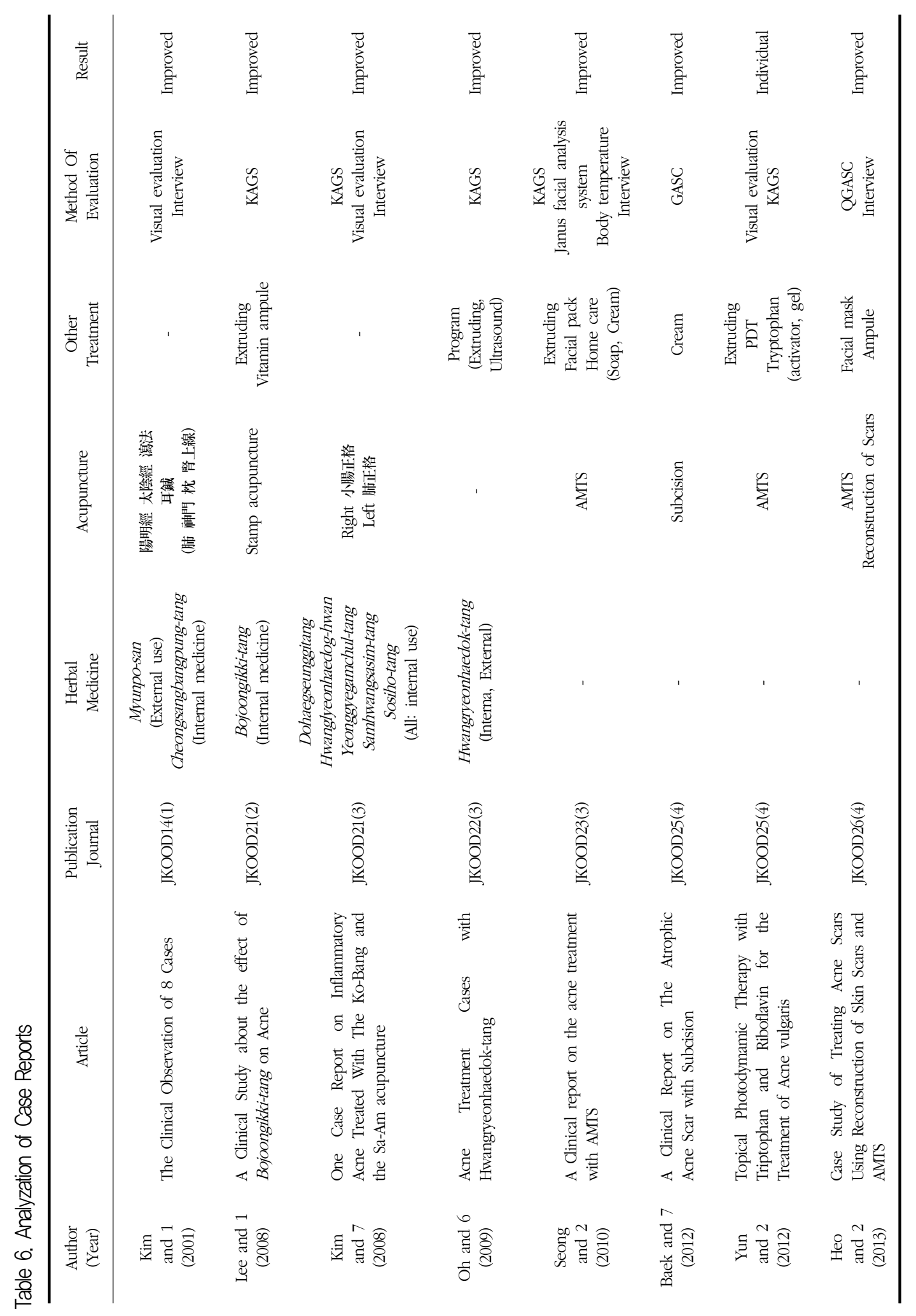


료법에 대한 관점이 부족하여 환자들에게 한의학적 여드름 치료에 대한 인식이 제대로 정립되고 있지 못 하는 실정으로 보인다.

현대사회의 미용에 대한 관심이 높아지고, 치료에 대한 효과가 즉각적으로 눈에 보이는 피부 질환의 특 성상 한의학의 피부질환에 대한 치료법은 나날이 새 로워지고 다양해지고 있다. 최근에 임상에서는 자동 미세침법, 재생침법, 매선 등 기존의 침법의 한계를 극복하고 좀 더 효과를 극대화시키기 위해 새로운 치 료법들이 다양하게 시도 되고 있는데, 이에 따라 각 치료법에 대한 효과와 부작용, 그 근거에 대한 이론을 정립해야 할 필요성이 있다고 생각된다.

한방안이비인후피부과 학회지에 보고되어온 여드름 관련 논문을 통해 여드름의 한방 치료에 관하여 기존 에 진행되어 온 연구들에 대한 분석 및 성찰함으로써 향후 여드름의 한의학적 치료에 대한 연구 방향을 모 색하고 발전시키고자 하였다.

이에 저자는 1998년 대한외관과학회지부터 2014년 도 27 권 2호까지 한방안이비인후피부과 학회지에 개 재된 여드름 관련된 논문 29편을 찾았으며, 이중 원저 가 17 편, 증례보고가 8편, 종설이 4편으로 나타났다. 2000년 이전에는 여드름과 관련된 단 한편의 논문도 찾을 수 없었다. 여드름이라는 한가지 질환에 대한 논 문이기 때문에 종설 논문이 다른 유형의 논문들보다 많이 부족한 것으로 생각된다. 원저 논문의 경우 2000년부터 꾸준히 높은 비율을 보이고 있으나, 증례 보고 논문은 2007년 이전에는 단 한편의 논문만이 있 었던 것에 비해 2008년 이후로는 꾸준히 논문이 개재 되고 있다. 이는 피부미용의 사회적 관심이 높아짐에 따라 새로운 여드름 치료법이 개발되어 그 효과를 입 증하기 위한 논문들이 나오기 때문이라고 보인다. 전 체 논문수도 2007 년 이후로 29 편의 논문 중 21 편의 논문이 개재되어 최근으로 올수록 논문이 집중되는 경향을 보였다.

원저 논문의 경우 기술적 연구(Descriptive Study), 분석적 연구(Analytic Study), 실험적 연구(Experimental
Study)로 분류해보았을 때, 실험적 연구가 10 편으로 가장 많았고 기술적 연구가 7편, 분석적 연구가 0 편이 였다. 기술적 연구는 연구의 대상이 되는 현상을 그대 로 기술하는 것을 목적으로 한 논문이며 분석적 연구 는 인과관계를 파악하고자 시행하는 연구로 특정요인 과 특정요인에 간섭을 받지 않는 비교 대상과의 비교 검증하는 과정을 거친 논문이다. 실험적 연구와 기술 적 연구에만 편중된 것은 연구의 다양성 추구에 있어 서 아쉬운 부분이였다. 여드름은 원인균이 거의 규명 이 되어있는 상태로 그 원인균이나 염증을 일으키는 균을 대상으로 하는 실험적 연구가 많이 이루어졌다. 다만 여드름이 발생하는 원인으로 생활습관과 관련된 다양한 인자들이 결합되어 복합적인 형태를 띄고 있 고, 임상적으로 위험한 증상을 야기시킨다기 보다는 미용적인 목적의 치료가 많기 때문에 상대적으로 분 석적 연구의 필요성이 낮아진 것으로 보인다. 실험적 연구는 대부분 시약으로 탕약 추출물과 본초 추출물 을 가지고 이루어 졌으며 항균효과와 항염증효과를 증명하는 논문이 가장 많았다. 사용된 탕약으로는 가 감비파청폐음, 연교패독산가미방, 가감청상방풍탕, 갈 근해기탕가감, 전도산 등이 사용되었고, 본초는 유황, 현호색, 자초 등이 있었으며, 임상시험용 제품에는 고 삼추출물과 화피추출물 등이 있었다. 기타 산성수, 박 하뇌와 백선피 유황등으로 만든 외용제가 있었다. 이 중 가미비파청폐음, 연교패독산가미방, 유향, 가감청 상방풍탕, 여의금황산, 전도산은 항염증 효과가 있었 으며, 현호색은 향균효과에 유의한 것으로 나타났다.

임상실험 관련 논문은 두 편으로 고삼 추출물과 화 피 추출물을 함유한 여드름성 피부에 사용하기 적합 한 화장품의 효능을 밝히기 위한 환자대조군 화장품 임상시험 논문이었다. 최근 한약을 활용한 한방 화장 품에 대한 효능이 각광받으면서 한의계 뿐만 아니라 미용학계를 비롯한 기타 다른 분야들에서 화장품 임 상시험 및 특허에 관한 연구가 활발해지고 있는데 앞 으로 시행될 여드름 관련 임상시험은 무작위배정, 이 중맹검, 객관적인 진단기준 등을 통해 연구의 질을 높 
여야 할 것으로 생각된다.

환자표본을 이용한 논문은 총 9편으로 기술적 연구 7편과 실험적 연구의 임상실험 연구 2편 이 있다. 그 중 대부분이 20 30명대의 환자군(55.6\%)을 상대로 연구를 진행했으며, 변 등은 일반인 535명이라는 상 대적으로 큰 인원을 대상으로 설문지를 시행해 기술 적 연구를 진행하였다.

종설 논문을 살펴보면 국내 문헌을 중심으로 분석 한 논문이 3편, 북미와 유럽 등의 해외 논문을 중심으 로 분석한 논문이 1 편이였다. 목적 주제별로 구분지 어 보면 2편의 논문이 여드름의 외용약에 관한 논문 이며, 한 편은 여드름 치료와 관련된 최신 임상 연구 동향에 관한 논문이며 나머지 한편이 병인과 증상, 치 료법을 통괄 정리한 질환 자체에 관한 논문이었다.

증례보고 논문은 각 증례에 사용된 치료법을 한약 치료, 침치료, 기타치료, 평가방법 등의 항목으로 나 누어 분석하였으며 이를 통해 여드름 치료에 다용되 는 내복약과 외용약, 기타 시술법 등을 알 수 있었다. 총 8 편의 논문 중 한약 치료만을 단독 시행한 경우는 1 편(12.5\%) 이였으며, 침 치료를 단독 시행한 경우는 4편(50\%), 한약과 침 치료를 병행한 경우가 3편 (37.5\%) 이엇다. 한약 치료법을 시행한 4편의 논문 중 외용약을 사용한 논문은 2 편이였으며 외용약과 내 복약을 병행하여 치료 하였다. 사용한 외용약으로는 면포산, 황련해독탕가미 발효액이 있었고, 내복약으로 는 청상방풍탕, 보중익기탕가미, 도핵승기탕, 황련해 독환, 영계감출탕, 삼황사심탕가미, 소시호탕 등이 있 었다. 기타 동반된 치료로는 압출이 4편으로 가장 많 았고 그 외에 광역동, 앰플, 한방 마스크팩, 크림 등이 병행된 것으로 나타났다. 윤의 논문 외에 7편 논문의 새로운 치료법과 외용한약의 경우 모두 결과가 호전 이거나 유의하여 한의학적 여드름 치료법이 효과가 있음을 알 수 있지만 치험례 숫자가 부족하여 치료효 과를 정립하기에는 아직 미흡한 부분이 많다.

증례보고 논문의 경우 8 편 중 침 치료 시행 논문이 7편이었는데 2010년 이후로는 모두 자동미세침법과
절개침 등 최신의 치료법에 대한 논문이었다. 미용목 적의 여드름 치료요구가 많아짐에 따라 탕약보다는 빠른 시일 내에 시각적인 효과가 눈에 보이는 치료법 들이 등장했고 그에 맞춰 효과를 검증하는 논문들이 나온 것으로 보인다. 특히 백과 허의 2 편의 논문은 여 드름흥터 치료에 목표를 맞춘 논문으로 환자들이 미 용의 목적으로 여드름을 치료하고자 하는 경향을 확 인할 수 있다.

자동미세침법(Auto-Microneedle Therapy System, AMTS)은 한의학에서 불리우는 皮膚鍼療法에서 기원 하여 현대에 발전된 형태로 주름과 여드름, 반흔성 피 부질환에 응용되는 미세침시술의 일종이다. 미세침시 술은 인위적으로 피부에 상처를 내어 피부 자체의 상 처 치유 메카니즘을 이용하여 자연적인 콜라겐 재생 을 유도하고, 미세구멍(micro hole)을 만들어 경피약 물전달체계(Transdermal Drug Delivery system, TDDS)을 이용하는 효과가 있다. 최근 미세침시술은 도장침, 롤러 방식에서 발전하여 기계를 이용한 자동 미세침시술로 많이 활용되고 있다9).

절개침법은 진피절개술의 시술과 한의학적 자락요 법의 개념을 결부한 것으로 시술 과정을 크게 3 단계 로 나눌 수 있다. 우선 절개침을 흥터 함몰부 아래부 분까지 자입하고 섬유성 띠를 절개한다. 두 번째로 자 입된 침을 좌우로 움직여 이차적으로 섬유성 띠를 끊 는다. 세 번째로 끊긴 섬유 띠 아래로 혈액의 유입을 유발하여 재생을 촉진한다. 보통 패인 형태의 여드름 흥터는 섬유성 띠가 진피의 아래층에서 표층근건막체 계(superficial musculo aponeurotic system, SMAS) 까지 연결되어 있는데 이를 절개함으로써 함몰된 부 위가 위로 올라가고 손상된 조직사이로 유출된 혈액 은 공간을 만들고 동시에 새로운 교원질의 생성에 도 움을 준다 ${ }^{10)}$.

증례보고 논문에서 평가척도로 가장 많이 사용된 것은 한국형 여드름 중증도 시스템(KAGS)로 증례논 문 5편에서 평가척도로 사용되었다. KAGS는 2004년 국내 5 개 의과대학 의료진이 공동 개발한 것으로 얼 
굴에 발생한 병변(구진 결절 반흔 등)의 개수와 형태 에 따라 크게 6단계로 나뉜다 ${ }^{11)}$ KAGS는 간결하고 판단하기 쉬운 장점이 있지만 한의학적인 변증 및 진 단과의 접점이 부족하여 추가적인 방식의 평가를 통 해 치료효과를 판단할 필요가 있다고 생각된다. 여드 름 흥터 치험례에서는 여드름 흥터 질적 등급체계 QGASC(Qualitative Global Acne Scarring Grade System)와 정량적 흥터 등급체계 GASC(Global Acne Scarring Classification)를 사용하였는데, QGASC는 흥터의 형태, 증상 심화도에 따라 여드름 흉터의 중등 도를 평가하는 등급체계로 2006년 Goodman에 의해 소개되어 임상에서 여드름 흉터를 질적으로 평가하는 도구이고, GASC는 병변의 개수, 흉터의 형태, 중등도 에 따라 여드름 흥터의 중등도를 평가하는 등급체계 로 역시 2006년 Goodman에 의해 소개되어 임상에서 여드름 흥터를 정량적으로 평가하는 도구이다 ${ }^{10,12)}$. 원저 논문에서 사용된 평가 척도로는 2006년 이후로 한국형 여드름 중증도 시스템(KAGS) 2편, 여드름 중 증도 시스템(GAGS), Skindex-29 등이 있었고 그 이 전에는 육안평가와 문진 등을 평가 지표로 사용하였 다. 이 중 GAGS를 사용한 논문은 한편이 있었는데 GAGS는 안면부위, 가슴 및 등 부위를 모피지선 단위 (Pilosebaceous units)의 표면적 분포 및 밀도에 따라 6개의 구간으로 나누어 분석하고, 각 구간마다 고유의 factor를 부여한 후 병변 부위에 따라 점수(Local score)를 주어 Global score에 반영하고 등급을 정하 여 평가하는 방식이다 ${ }^{13)}$.

여드름의 한방 치료에 대한 환자들의 요구가 증가 함에 따라 여드름의 한방치료에 관한 논문수 또한 증 가하고 있고 특히 증례보고 논문의 증가가 두드러지 나 아직까지 여드름 관련 한방 논문의 수가 많이 부 족한 실정이다. 향후 여드름과 관련된 임상시험 논문 과 증례 논문 등의 임상적인 연구가 보다 더 활발히 이루어져야 할 것으로 생각된다. 증례 논문에서 볼 수 있는 최근 새로운 외치법에 관한 연구에 있어서 한방 적인 진단과 그에 따른 한방 외용제나 내복약과의 병
행, 호전도의 상관관계를 조사할 필요도 있다고 보인 다. 또한 아직 부족한 증례 환자수를 좀 더 누적하여 단순 증례 수준의 연구가 아닌 호전도의 통계적 유의 성까지 확보한다면 한방 여드름 치료에 대한 환자들 의 신뢰성을 높일 수 있는 좋은 자료가 될 것이다.

본 논문의 취약점은 한방 안이비인후피부과학회지에 국한된 점으로 향후 한의학적 여드름 치료의 포괄적 인 동향을 살펴보기 위해서 보다 많은 논문을 조사하 고 분석을 시행할 필요성이 있다고 생각된다.

\section{V. 결 론}

1998년 대한외관과학회지부터 2014년도 27권 2호 까지 한방안이비인후피부과 학회지에 개재된 여드름 관련 논문 29편을 분석해본 결과 다음과 같은 결론을 얻었다.

1. 원저가 17 편, 증례보고가 8 편, 종설이 4편으로 나 타났다.

2. 원저 논문의 경우 실험적 연구가 10 편으로 가장 많았고 기술적 연구가 7편, 분석적 연구가 0 편이 였다.

3. 증례보고 논문은 최근 새로운 치료법들의 대두로 인해 증가하는 추세이다.

\section{References}

1. Korean Dermatological Association Textbook Compilation Committee. 5th Edition Dermatology. Seoul:Ryo Moon Gak. 2008:446-54.

2. Jeong JY. Acne. Seoul:MD world. 2007:15,32-5,63-5,142-58,207-8,10-2,214, 517-38, 711-2, 812-25.

3. Jeong JY, Ha CM. Primary care of skin disease revision vol. 1. Chungbuk:MD world. 
2006:391-8.

4. Lee SH, An BG. The Quality of Life of Acne Patients. Korean Journal of Dermatology. 2003;41(10):1274-5.

5. Yoshiki Miyachi, Masahiro Takigawa, Fukumi Furukawa. The Latest Acne Treatment Techniques. Seoul:Koon Ja Publishing, Inc. 2009:220.

6. Korean Tranditional Dermatological Association Textbook Compilation Committee. Text of Tranditional Korean Dermatology \& Surgery. Busan:Sun Woo. 2007:486-7.

7. Son MS, Song GJ, Jang SJ, Lee HS. Analysis of Articles Published of The Korean Society of Emergency Medicine. 1997;(1):24-30

8. Kang WH. Atlas of Skin Disease 2nd Edition. Seoul:Han Mi. 2008:205-7

9. Seong EJ, Jo EH, Park MC. A clinical report on the acne treatment with AMTS. J Korean Med Ophthalmol Otolaryngol Dermatol. 2010;23(3):236-46

10. Heo JE, Yun JM, Shin SH. Case Study of Treating Acne Scars Using Reconstruction of Skin Scars and Auto Microneedle Therapy System. J Korean Med Ophthalmol Otolaryngol Dermatol. 2013;26(4):127-34.

11. Sung KJ, Rho YS, Choi EH, Oh JJ, Lee JH, Kim SW, Kim NI. Korean Acne Grading System. Korean J Dermatol 2004;42(10): 1241-7.

12. Baek SC, Hong MS, Jegal H, Jin YH, Joo TM, Lee SJ. Jo EH, Park MC. A Clinical Report on The Atrophic Acne Scar with Subcision. J Korean Med Ophthalmol Otolaryngol Dermatol. 2012;25(4):80-8.

13. Park SY, Na CS, Jeong WC, Lee JC. A
Clinical Study for Effect of Herbal Cosmetics Containing Cortex Betulae Platyphyllae Extract Complex on Acne. J Korean Med Ophthalmol Otolaryngol Dermatol. 2013;26(3):1-19.

14. Kang SH, Kim GJ. Effects of Lithospermum erythrorhizon on the cytokine gene expression in human keratinocytes. J Korean Med Ophthalmol Otolaryngol Dermatol. 2013; 26(1):50-62.

15. Yun YH, Kim TY, Choi IH. Topical Photodynamic Therapy with Triptophan and Riboflavin for the Treatment of Acne vulgaris. J Korean Med Ophthalmol Otolaryngol Dermatol. 2012;25(4):89-98.

16. Joo HA, Bae HJ, Hwang CY. A Literature Study about Comparison of Eastern-Western Medicine on the Acne. J Korean Med Ophthalmol Otolaryngol Dermatol. 2012;25 (2):1-19.

17. Lee WG, Kim BH, Jeon SW, Kim KS, Nam HJ, Yoon-Bum Kim. The Latest Trends of Treatment for Acne Vulgaris in PubMed. J Korean Med Ophthalmol Otolaryngol Dermatol. 2011;24(2):41-56.

18. Baek SC, Jo EH, Mendgerel, Park MC. Effect of Sophorae Radix-Skin Lotion on Acne. J Korean Med Ophthalmol Otolaryngol Dermatol. 2011;24(1):111-20.

19. Lee JR, Park SJ, Kim YW, Cho IJ, Byun SH, Kim SC. Comparison of Antimicrobial effects of Corydalis tuber and processed Corydalis tuber against Propionibacterium acnes. J Korean Med Ophthalmol Otolaryngol Dermatol. 2011;24(3):17-26.

20. Oh CS, Kim MS, Kim Il, Kim HY, Park SI. Choi SI, Hong DS. Acne Treatment Cases 
with Hwangryeonhaedok-tang. J Korean Med Ophthalmol Otolaryngol Dermatol. 2009;22(3):228-36.

21. Tak MJ, Tark MR, Yoon HJ, Ko WS. A Clinical Report of Sasang Constitutional Prescription Treatment on 81 Acne Patients. J Korean Med Ophthalmol Otolaryngol Dermatol. 2009;22(2):210-22.

22. Kim HY, Sung EJ, Yun CS, Yun Cheol, An MS, Kim HY, Jo EH, Park MC. One Case Report of Inflammatory Acne Treated With The Ko-Bang(古方) and the Sa-Am acupuncture. J Korean Med Ophthalmol Otolaryngol Dermatol. 2008;21(3):226-34.

23. Kim MA, Kim MB, Shin SH, Byun SM, Ko WS, Lee HS, Park SG, Yoon HJ. The study on external treatment of oriental medical care on acne. J Korean Med Ophthalmol Otolaryngol Dermatol. 2008;21(2):102-11.

24. Jin-Ah, Hong SU. A Clinical Study about the effect of Bojoongikki-tang on Acne. J Korean Med Ophthalmol Otolaryngol Dermatol. 2008;21(2):191-7.

25. Son BK, Choi IH. Correlation between Prognosis and Factors on Acne Patients. J Korean Med Ophthalmol Otolaryngol Dermatol. 2008;21(1):113-20.

26. Seo ES, Hwang CY, Kim NK. Experimental study of Gagam-Cheongsang BangPungTang on the Anti-inflammatory Effects. J Korean Med Ophthalmol Otolaryngol Dermatol. 2008;21(2):54-70.

27. Park YH, Jung MY, Kim DS, Park SY, Kim $\mathrm{JH}$, Choi JH. The Results of Yangdorak and D.I.T.I, according to Deficiency of Excess of Acne Patients. J Korean Med Ophthalmol
Otolaryngol Dermatol. 2007;20(2):171-8.

28. Choi KH, Seo HS. The Effects of Jeondo-san on Anti-Inflammation and Anti-Propionibacterium acnes. J Korean Med Ophthalmol Otolaryngol Dermatol. 2007;20(2):89-101.

29. Yoo JG, Seo HS. The Effects of Yeouigeumhwang-san on Anti-Inflammation and Anti-Propionibacterium acnes. J Korean Med Ophthalmol Otolaryngol Dermatol. 2007;20(2):77-88.

30. Lee SY, Seo HS. The Effects of Sulfur extract on Anti-Inflammation and Anti-Propionibacterium Acnes. J Korean Med Ophthalmol Otolaryngol Dermatol. 2007;20(2):68-76.

31. Byun HS, Um YS, Hur IH, Sim SY, Kim KJ. The Quality of Life of Skin Disease Patients, Particularly Acne Patients. J Korean Med Ophthalmol Otolaryngol Dermatol. 2006;19 (1):65-78.

32. Yu HJ, Choi IH. A Practical Application on the External Treatment of Acne (A Focus on the Medical Herbs Published in the Woman's Monthly Magazines). J Korean Med Ophthalmol Otolaryngol Dermatol. 2004;17 (1):34-44.

33. Lim JH, Oh EY, Jee SY. A Clinical Report about the Effect of Chungsangbangpungtang on Acne. J Korean Med Ophthalmol Otolaryngol Dermatol. 2003;16(2):177-88.

34. Seo HS, Hong SH. The Clinical Study on the Effect of Spread Acidic Ionized Water on Acnes Disease. J Korean Med Ophthalmol Otolaryngol Dermatol. 2003;16(1):154-8.

35. Kim SB, Kim KJ. Effect of the Addition Temperament Drugs of Yeongyopaedock-san on Acne in the State of Inflammation. J 
Korean Med Ophthalmol Otolaryngol

Dermatol. 2002;15(1).

36. Kim JS, Kim GJ. The Clinical Observation of 8 Cases of Acnes Diseases. J Korean Med Ophthalmol Otolaryngol Dermatol. 2001;14(1).

37. Choi IH. A Clinical study of Recurrent Acne in the Oriental Medicine. J Korean Med Ophthalmol Otolaryngol Dermatol. 2000;13(2).

38. Yim HS, Chae BY. The Experimental Study of Gagambipachungpe-Eum on Acne. J Korean Med Ophthalmol Otolaryngol Dermatol. 2000;13(1). 